\title{
A career in biophysical chemistry beckons: thoughts on the beginning of a journey from a young female scientist
}

\author{
Charlotte K. Rouse ${ }^{1}$
}

Received: 10 December 2016 / Accepted: 20 December 2016/Published online: 9 January 2017

(C) International Union for Pure and Applied Biophysics (IUPAB) and Springer-Verlag Berlin Heidelberg 2017

Having just submitted my Ph.D. thesis, I have arrived at a point of major change in my life as I prepare to embark on my first professional position. Depending on the location, this will also likely have a massive influence on my personal life. It is a time filled with uncertainty and trepidation, but also excitement, as important decisions are about to be made that will shape the future of my scientific career. I would feel like a fraud trying to give advice to others in my position, but perhaps for those approaching a similar career stage, I can offer some words of encouragement. Hopefully, my thoughts may also provide pause or insight for those already in senior positions, with respect to the challenges facing young people in academia today.

\section{Trying to understand the rules of the game}

Career development and progression, outside of the confines of the highly controlled rubrics in education, is intimidating and more than a little bewildering. As research scientists, we are trained to approach problems in a logical way, so how do we begin to tackle the general problem associated with how to advance in our scientific career? The usual scientific tools that allow us to critically analyse data, form hypotheses and establish cause and effect do not necessarily apply when charting an individual course. Any previously established knowledge is often gleaned from a small, biased sample (current academics), and, as the pace of change continues to increase, is the advice given to us by those who gained success ten years

Charlotte K. Rouse

charlotte.rouse@anu.edu.au; charlottekirstyrouse@gmail.com

1 The Australian National University, Canberra, Australia ago even relevant today? Furthermore, if their position seemed to result from the existence of a close personal contact, e.g. from strong support of their former supervisor, should we disqualify their advice as an outlier resulting from nepotism? Alternatively, should such advice convince us to prioritise the cultivation of connections with powerful academics over the pursuit of scientific inquiry? Importantly, how do we define success, especially when careers are so closely linked with our personal lives? How can cause and effect be correlated when, within each data point, each person's career, there are a multitude of factors? There is no possibility of using controls, and certainly experiments cannot be performed in replicate. Although career decisions cannot be approached in the same way as a laboratory experiment, it is my strong feeling that neither should they be based on completely haphazard actions and should never be left to chance.

\section{In the beginning}

Entering undergraduate studies at Newcastle University in the U.K., I ticked the boxes for a multitude of STEM higher education targets: coming from a non-tertiary educated family, a poorly performing, rural secondary school and female. But within Chemistry at least, I never noticed. For me, University was a great levelling platform and the only thing I ever felt judged on, or how my lecturers treated me, was my grades. There were few options for module choices within my degree, providing a broad, solid undergraduate education in Organic, Inorganic, Physical and Medicinal Chemistry which has served me well in my post-graduate studies. In today's academic environment, where courses are tending towards a mix and match of student choice, I would suggest that the adoption of such a common core curriculum has many more strengths than weaknesses, and produces a higher quality 
student 'product'. Not becoming too specific too early was of great benefit to me in approaching cross-disciplinary research and has proven extremely advantageous when it comes to communicating to a general scientific audience. Like most things in life that are difficult, my undergraduate experience, although incredibly challenging, was also very rewarding. In my second year, I won funding for a summer research scholarship, and an entirely new world outside of lecture material was revealed. An exciting project, coupled with the encouragement and support of an excellent supervisor, cemented my passion for research, and I returned for a second summer research scholarship before starting and completing a Master's research project in 2009.

\section{Time for a break}

Despite developing an interest in research, I did not feel ready to commit to a Ph.D. immediately after graduation. I had no idea what I wanted for a career and worked for a couple of years in non-scientific positions to pay off my undergraduate student debt. After accumulating some savings, I quit my job, took a one-way flight to Brazil and spent the next twelve months backpacking around South America (Fig. 1). It was an incredible period of time, not just for the amazing experiences and all the people I met but also because I was lucky enough to be in a position where the only pressure I had was deciding where to take the next bus to. Because I was travelling solo, the decision was all mine. The only nod to 'real life' during my travels was the decision to apply for a Ph.D. scholarship. Taking a global viewpoint, this process was at first overwhelming considering all the potential supervisors in Universities and Institutions all over the world. Having undertaken projects in supramolecular chemistry at undergraduate level, however, I at least knew the area I wanted to study and I

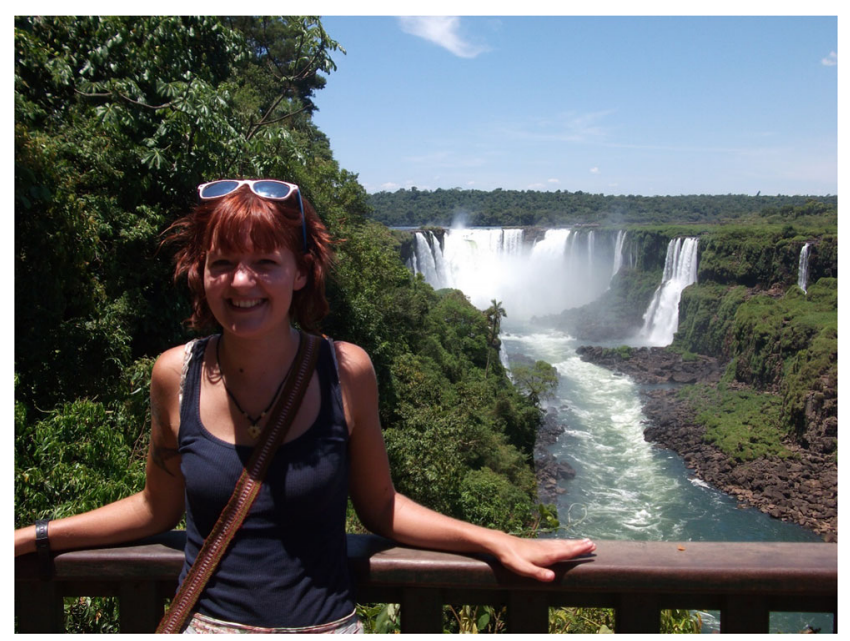

Fig. 1 At the Foz do Iguaçu (Argentina/Brazil), pre-Ph.D also knew that I wanted to move beyond the familiarity of the U.K. higher education scene. Like a lot of others in that stage, my strategy largely consisted of googling research groups in top performing Universities of countries that I thought that might like to live in for four years.

\section{Starting the Ph.D.}

Although my research methods were not the most thorough, I picked a great place to study in The Australian National University (ANU). ANU has great facilities, a large, multidisciplined department, and I love living in Australia. A $\mathrm{Ph} . \mathrm{D}$. is a long, hard journey, so it is important to live somewhere where you can also enjoy life, and for me there is no better antidote to the stresses of study than spending a weekend SCUBA diving and camping on the New South Wales coast. Having recently submitted my thesis, I can say without reservation that my Ph.D. experience has been very positive. I was lucky enough to have a supervisor who gave me guidance where needed, but also allowed me free reign on the direction of my project. As a result, my work has truly followed my own interests, initially in host-guest chemistry and selfassembly and ending in peptide structure, thermodynamics and function with a focus on metal-binding. As my Ph.D. research lay at the interface of supramolecular chemistry and biophysical chemistry, I was also keen to learn as many new techniques as possible, and borrowed heavily from the methods and knowledge of others in both disciplines. By the time of submission, I felt I was very close to achieving what I think defines a Ph.D. conferee, an accepted member of the scientific community, capable of performing independent research.

\section{Taking the next step}

I have never stopped learning and I would never want to, which is why I am now pursuing the next step in an academic career. It was not a simple decision however, because as much as I love doing research, there are many negatives that are particular to academia. Three that I am particularly concerned with are productivity, gender equity and research integrity (Fig. 2).

With regards to research productivity, of course there is a lot of pressure to continually achieve results, and we all know that we must publish or perish. In experimental fields, this could mean a lot of hard work with little or no success. The potential for so much effort without reward not only impacts on career progression but also has, I believe, a detrimental psychological effect. Being productive in research also requires another skill, completely unrelated to practical science, that is, awareness of publishing strategy. The peer review 
Fig. 2 Uncertainties in an academic career

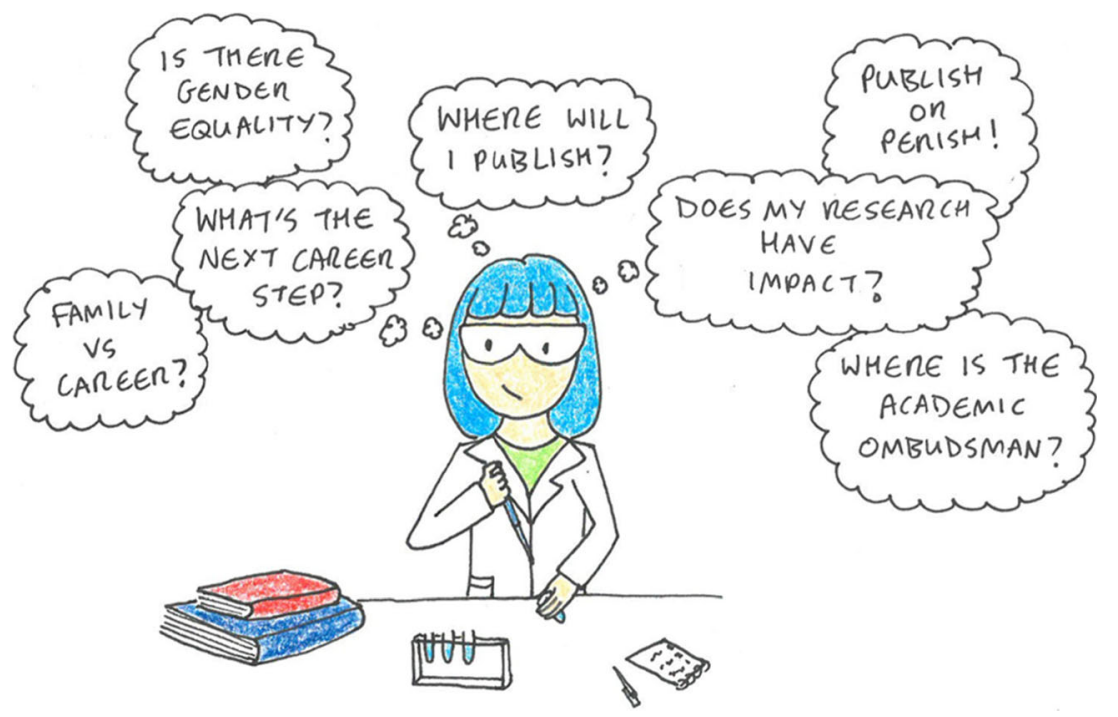

system exists to provide validation and to highlight important discoveries to the wider community; however, my concern is that the main focus is becoming fixed on impact factor rather than the science itself. Do senior scientists become blind to such considerations as the standard question becomes 'where was your paper published?' rather than 'what was your paper about?'.

With regards to gender equity, there is very little stability attached to any academic position, and it is an expectation that you will probably be required to move yourself and your family across the globe several times during your working life. For me, this is of particular importance as I reach an age where I begin to consider starting a family, and also highlights the differences in roles that males and females typically play. It is not considered unusual, for example, for a female to relocate for her partner's job, but it is still somewhat unconventional for a male to do likewise. Gender equality has made great progress; however, we are entering a new phase, a modern version of equality, where it is not enough to consider fairness in terms of the number of women in science and high-ranking positions, but also how this creates different pressures on personal life. I find myself meeting challenges that, growing up, I could never have envisaged. I have been so conscious of striving to be in a situation where I am highly valued in work life, it has taken me by surprise that I now have to remember that I also need to demand a personal life for myself. Although academia is moving closer to the expectations of other industries in this regard, to some extent there will always be a price exacted for the freedom to explore your own curiosities and to be funded to do so.

With regards to research integrity, to my mind, research is an unusual occupation in that it is almost entirely administered by its members, with no ombudsman or customers to answer to. This system potentially allows for dubious practices such as self-citing, the formation of publishing cliques, sham collaborations with high impact authors and the rubberstamping of degrees for the sake of student numbers. This is all behaviour that could be eradicated within a single generation, but what actions will incentivise such a positive future path? I feel that this is an important question not just for the good of science but also for the good of public perception of science, which in turn translates into funding.

\section{Towards a future career}

The main reason I entered into scientific research was the opportunity to contribute to society, and it this ethos that, for me, overrides all the negative points I associate with academia. I have made the decision to pursue my scientific passion and am now actively planning for a research career. As I look to the future with a positive disposition, I have great faith in the dedication and integrity of my peers, and am confident that they will drive towards enacting positive change within academia, ensuring that the best and brightest stay in research, of which I plan to be one.

Acknowledgements The author gratefully acknowledges support from The Australian National University (Ph.D. scholarship), Newcastle University (summer research scholarship) and The Nuffield Foundation (summer research scholarship).

\section{Compliance with ethical standards}

Conflict of interest Charlotte Rouse declares that she has no conflicts of interest.

Ethical approval This article does not contain any studies with human participants or animals performed by the author. 